\title{
Intrinsic Motivation and Self-Directed Learning Relationship: Strive for Adult Learning Character Formation
}

\author{
Akbar, S. ${ }^{1}$, Claramita, M. ${ }^{2}$, Kristina, T.N. ${ }^{3}$
}

\begin{abstract}
Background: Intrinsic Motivation and Self-Directed Learning (SDL) as two characteristics of adult learners are believed to be performed in a Problem Based Learning (PBL) curricula. The Medical Faculty of Universitas Gadjah Mada (UGM) has been implementing PBL curricula for approximately 20 years. It is important to know the results of the application of PBL curricula in regards to the efforts in performing the character of adult learners.
\end{abstract}

Methods: This is a cross sectional study design, which uses questionnaires as the instrument. Research subjects were third year students from three Study Programs (General Medicine, Health-Nutrition, and Nursing). The questionnaires used were Intrinsic Motivation Inventory (IMI) and Self Directed Learning Readiness Scale (SDLRS) Fisher questionnaire.

Results: A total of 451 students $(86.07 \%)$ were willing to fill out the questionnaires completely. The average value of the third-year students' intrinsic motivation was 26.67 from the maximal value of 35 , and SDLRS score was 138.85 from the maximal value of 185 . The Person correlation on the intrinsic motivation relationship with SDL was only $0.234(\mathrm{r}<0.35)$.

Conclusions: The results show that the character of adult learners have not being well performed in the UGM Medical Faculty. Further researches need to be conducted on the factors that affect the formation of adult learners' character that includes cultural, motivation, students' perception and learning approach factors.

Keywords: problem-based learning, self-directed learning, intrinsic motivation, adult learners.

\section{Background}

Adult learners are people who have learning character; they have Self-Directed Learning (SDL), use experiences from various learning resources, have high learning readiness, oriented directly to apply knowledge, and have a high intrinsic motivation in learning (Knowles, 1970). The ability to have lifelong learning can be obtained when the characteristics of adult learners have being performed.

${ }^{1}$ Medical Faculty of Universitas Islam Sumatera Utara

${ }^{2}$ Medical Faculty of Universitas Gadjah Mada

${ }^{3}$ Medical Faculty of Universitas Diponegoro

Corresponding author:

Surya Akbar

Medical Faculty of Universitas Islam Sumatera Utara (UISU) JI. Karya Bakti, No. 34, Pangkalan Mansyur, Medan Johor, Medan, Indonesia.

Email:dr.akbar9@gmail.com
SDL is the most important characteristic in the adult learner (Merriam, 2001; Abela, 2009), because SDL is required to have a lifelong learning ability (Murad \& Varkey 2008; Bidokht \& Assareh 2011). To form the characteristic of SDL inside the learner, a learning method which requires learners to perform SDL abilities in the learning process are needed (Loyens et al, 2008).

Problem Based Learning (PBL) curricula is a method of learning that is believed to be able to form SDL within the learner (Hmelo-Silver ,2004). PBL curricula successfulness in forming the characteristic of SDL within the learner cannot be separated from the influence of motivation inside the learner (Harun et al, 2011). Intrinsic motivation that persists in performing SDL skills will form the SDL characteristic within the learner (Nenniger, 1999). 
The character of an adult learner is said to be performed through the PBL curricula if the intrinsic motivation and the SDL ability of the students has an equally high score or if the correlation between the two characteristics is strong. This assumption based on concept of andragogy by Knowles (Smith, 2013) who said that the adult learners as a person who have high SDL ability and high intrinsic motivation.

Williams (2004) found that nursing students who are taught using PBL curricula have the SDL ability. Malta et al. (2010) report an increase in the SDLRS score for students of physical therapy and occupational therapy by comparing the SDLRS score at the beginning of the semester and at the end of semester. Cultural factors have an influence in the implementation of PBL curricula as an attempt to form the character of SDL within the learner (Ahmad \& Majid 2010; Frambach et al., 2012).

There are the differences between Asian countries and American or European countries, because the hierarchy in the Eastern cultures is strongly felt (Claramita et al., 2013). Therefore, the implementation of PBL curricula which uses independent learning as a learning method in Asian countries, including Indonesia, to face some challenges. Lestari and Widjajakusumah (2009) report that $50 \%$ of third and fourth year students have a SDLRS score ranging between low to average. Further, Triatmojo (2013) states that the main problem for the implementation of Competency Based Curriculum (CBC) at the Medical Faculty of Universitas Gadjah Mada (UGM) was lack of students' intrinsic motivation. This phenomenon could be explained by the minimum interaction and dialogue between students and teachers and more one-way instructions from the teachers. (Claramita et al., 2013). Therefore, facilitating independent learning may be limited by this cultural context.

The UGM Medical Faculty is the oldest faculty which implements PBL curricula in Indonesia (Directorate of Higher Education, Ministry of Education and Culture Republic of Indonesia and Faculty of Medicine UGM, 1995). The Faculty of Medicine, UGM had implemented the PBL Hybrid curricula in $20 \%$ of the curriculum since 1992, and have been moving to the full PBL curricula from 2002 to the present. Based on this explanation, this study was conducted in order to analyse the results of the adult learners' character formation through the PBL curricula by looking at the relationship between intrinsic motivations and students' SDL ability in a culture with presumably limited interaction between students and teachers.

\section{Methods}

This research is a quantitative study with a cross sectional study design, which uses questionnaires as the instrument. The subjects were all third-year students from regular classes from three study programs: general medicine, nursing, and health-nutrition. Thirdyear students were selected under the assumption that they have been exposed long enough to the PBL curricula, so the assessment of SDL would be feasible. A total of 524 students were included in this study. Students from international class and students who still repeated the blocks were not included as the subjects in this study in order to maintain uniformity for the experience between the subjects of the study.

The instruments used in this study were the questionnaires of Intrinsic Motivation Inventory (IMI) and Self-Directed Learning Readiness Scale (SDLRS). The IMI questionnaire used in this study is validated by (McAuley et al., 1989). It consists of 18 question items with four subscale statements. Researchers only used interest/enjoyment (five-item statement) subscales because only these sub-scales actually measure intrinsic motivation (Deci \& Ryan, 2013). The SDLRS questionnaire was developed by (Fisher et al., 2001). It consists of 42 question items with three sub-scale statements.

The questionnaire used in this study is a questionnaire from Western-settings, so in order to be used in Indonesia, the researchers conducted a validation process for these instruments. Validation was performed for both of the questionnaires including content and construct validation. The process of questionnaire content validation was conducted in the following order: translating the questionnaire into the Indonesian language, which was done by all authors; conducting a readability test with five students from the Faculty of Medicine out of the research subject, and re-translating the questionnaire into English to see the suitability of the translated questionnaire to the original questionnaire (this was done by a lecturer in English). The construct validation process involved examining the internal consistency (Cronbach Alpha test) and conducting a convergent validity test (inter-sub-scale correlation test) of each questionnaire.

After receiving approval from the ethics committee, the researchers began this study. Students were asked about their willingness to follow the voluntary nature of this study. 
Students who were willing to participate in this study were asked to sign a consent form that was given along with the questionnaire. The first researcher explained the purpose of the study, the benefits, and how to fill out the questionnaire. He remained indoors when the questionnaires were completed; this was done to provide an explanation if there was a question from the questionnaire that was not understood by the students.

The benchmark to determine the level of SDL and intrinsic motivation of students was done by using a standard Likert scale (Colton \& Covert, 2007). A person is said to have a low intrinsic motivation, when the score was $<14$, average when the score ranged from 15-25, and high when the score was $>26$. The reference value for SDL ability of students from the SDLRS questionnaire was low when the SDLRS score was $<73$, an average SDL ability when the
SDLRS score ranges from 74-148, and a high SDL ability when the SDLRS score was $>149$. The relationship between intrinsic motivation and SDL was analysed using Pearson correlation test.

\section{Results}

A total of $451(86.07 \%)$ of all students in the third year from three study programs (524 people) filled out the questionnaires completely. The number of female students was greater than male students. The number of students' who came from high schools in Java was greater than students from high schools outside the island of Java (Table 1). The Pearson correlation values on the relationship between Intrinsic Motivation and SDLRS on over all third-year students showed a weak but significant correlation $(r=0.234, p=0.001)$.

Table 1: Characteristics of participants

\begin{tabular}{|c|c|c|c|c|c|c|}
\hline \multirow[b]{2}{*}{ Study Program } & \multicolumn{2}{|c|}{ Sex } & \multicolumn{4}{|c|}{ High School Origin } \\
\hline & $\hat{\sigma}$ & q & $\mathbf{N}$ & Java & $\begin{array}{l}\text { Outside } \\
\text { Java }\end{array}$ & $\mathbf{N}$ \\
\hline General Medicine & 91 & 166 & 257 & 201 & 56 & 257 \\
\hline Health-Nutrition & 7 & 87 & 94 & 87 & 7 & 94 \\
\hline Nursing & 5 & 95 & 100 & 88 & 12 & 100 \\
\hline Total & 103 & 348 & 451 & 376 & 75 & 451 \\
\hline
\end{tabular}

The result of the SDLRS Fisher questionnaire construct validation process was as follows: there are five invalid statement items: "I set a strict time limit to complete a task", "I set a specific time for studying", "When confronted with a problem that I cannot finish, I will ask for help to solve it", "I have to limit the things that I learned", and "I am aware of the limitations of myself". The invalid item then removed from the questionnaire. The total items in the SDLRS
Fisher questionnaire after removing the invalid items were 37 items with a Cronbach alpha value of 0.898 . The validation process for the IMI questionnaire showed that all of the items were proven valid, so there were no items removed from the IMI questionnaire $(\alpha=0.802)$. Table 2 illustrates that the intrinsic motivation of the three study programs was high, and mean value of SDL from the three study programs were moderate.

Table 2: IMI and SDLRS descriptive data

\begin{tabular}{lrrrrr}
\hline Questionnaire & Mean & 土 SD & Median & Min & Max \\
\hline \multirow{2}{*}{ Intrinsic Motivation SDLRS } & 26.67 & 4.14 & 27 & 8 & 35 \\
& 138.85 & 11.80 & 138 & 104 & 182 \\
\hline
\end{tabular}

\section{Discussion}

The SDL ability of third-year students obtained from the learning process using the PBL curricula in this study was moderate. These results contrast with what is expected from $\mathrm{PBL}$ curricula, which are expected to improve the students' SDL ability. Students who are at the end of the educational program are expected to have a high SDL ability (Malta et al., 2010). 
An assumption to explain these results is that the SDL ability of third-year student is probably still at the processing stage and has not yet become the character of the student. The definition of SDL can be viewed from two perspectives: SDL as a process and SDL as a self-attribute (Schmidt, 2000; Mann et al., 2011). Self-directed learning as a process is when a person has the initiative on planning, implementing, and assessing their own learning experience. Self-directed learning as a selfattribute when a person has the psychological maturity to learn so that the person has curiosity, interest, and orientation towards achieving their goals.

(Fisher et al., 2001) explained that the SDLRS is a questionnaire aimed to assess the degrees of attitude, abilities, and personal character of a person that are required in the process of selfdirected learning, while in the learning process, in the PBL curricula, learners are only taught to perform SDL skills (Schmidt, 2000). The learning process that requires students to perform SDL skills is not ensuring the formation of SDL within the learner. The SDL ability can be a characteristic within the student if the SDL ability is internalized. Therefore, the result of the moderate level for SDL in these students is reasonable.

Other evidence that showed undemonstrated SDL ability into a characteristic can be seen when the correlation test between the intrinsic motivation of students and students' SDL ability showed a very weak relationship. This is contrast to what is conveyed by Knowles on the concept of an adult learner (Andragogy). Knowles as cited by (Smith, 2013) through the concept of Andragogy said that an adult learner has portrayed characteristics such as: using experience as a learning resource, has selfdirected learning ability, has a readiness to learn, has an orientation to learn to focus on problem solving, and has intrinsic motivation in learning. Based on that concept, an adult learner should have a SDL ability and high intrinsic motivation.

The character formation for learners who have SDL ability, is not possible to take place in a short time. The learning process through the PBL curricula in medical education that only lasts about five and a half years, is not enough to form the characteristic of SDL within the learner. This is because the high school students in Indonesia - before entering college - may not be accustomed to learn by applying SDL abilities. The learning process in Indonesia, in primary, secondary, and high school, does not implement SDL ability. Several elementary, junior high, and senior high schools in Indonesia are already applying active selflearning, but it has not become a routine learning process when education takes place. Active independent learning is only done as additional material in the learning process at schools. This assumption is reinforced by the national curriculum that has been using when the study subjects still in elementary, junior high, and senior high schools, which does not give opportunity that students to learn independently and actively.

Frambach et al. (2012) stated that cultural factors influence the effectiveness of the PBL curricula implementation as a teaching method in Asian context. Thus, it can be interpreted that PBL curricula as a new learning method that might not commonly used in a particular cultural environment, would impede the process of its implementation. Although the use of these learning methods can still be implemented (by the process of adaptation of the learner), the results may be different from the application in the cultural environment that has been accustomed to use it. The PBL curricula has been adopted from America and Europe which have different cultures from countries in Asia. The cultures in American and European countries are familiar with the process of active self-learning, so the use of PBL curricula as an effort to improve the capabilities of SDL can be more readily applied. SDL character formation is easier to implement when the learners are already familiar with SDL ability compared to learners who have not been accustomed to SDL skills.

Obstacles in implementing PBL curricula in Asian medical schools caused by cultural differences, can be solved by strong support from the institution itself (Khoo, 2003). It is important for medical schools in Asia to prepare not only the environment that allows students to do learning process in PBL curricula but also provide the support of a faculty or staff that can help students learning in PBL curricula. Students also need to be aware with the process and benefit of the PBL curricula.

Learner interest (motivation) towards learning using PBL curricula does not guarantee the formation of learners' SDL ability. In this study, students who had implemented PBL curricula have high interest in the learning process. The $\mathrm{PBL}$ curricula is well believed to increase the interest of learners in the learning process. Student interest in PBL curricula may occur from problem solving scenarios that are given in the tutorial discussion (Hmelo-Silver, 2004). 
However, student interest in the given scenario is not always encouraging students to seek a deeper knowledge to explain the problem. Students in this study, may be accustomed to a passive learning process when they were in elementary, junior high, and senior high school so the desire to seek deeper knowledge of the scenario is not independently done. Students will seek knowledge simply by obtaining the learning objective (LO) and there is no further curiosity about the scenario presented (Wahid, 2013). It also explains the results in this study which shows a very low correlation in the relationship between students' intrinsic motivation and students' SDL.

Research conducted by Harun et al. (2012) explained that facilitators who systematically motivate students to learn in-depth would also perform motivation of in-depth learning. Based on the explanation, it can be seen that the motivation provided by the facilitator in the process of learning can encourage students to be able to achieve a certain goal, in this case, to increase students' SDL.

Based on the explanation above, the efforts to perform the characteristic of SDL within the learner by using a PBL curricula should pay attention to three things: the first one is the learner's characteristics (whether he/she already had SDL ability), second one is the characteristics of the learning environment that supports the students to improve SDL, and the last the role of the facilitator and lecturer in improving the students' SDL ability. All of these factors, when considered and well-executed, might be able to perform the character of SDL. The last factor should be explored in more rigorous research in medical education, considering the limited interaction between students and teachers in Asian context (Frambach et al., 2012; Claramita et al., 2013).

\section{Conclusions}

Based on the explanations above we can concluded that third year students of the UGM Medical Faculty, which uses the PBL curricula for more than 20 years, did not yet internalize the characteristics of adult learners. Future studies are needed to determine the factors that influence the formation of adult learners' character as well as the benefits of the use of PBL curricula in Indonesia.

\section{Limitations}

The data from this study are descriptive and correlative and do not yield basis for causal conclusions. The results are valid to the third year students of the UGM Medical Faculty and might not be valid for another Medical Faculties in Indonesia. Further research of the relationship between intrinsic motivation and SDL in another medical faculties is still needed to support this finding.

\section{Acknowledgment}

The authors would like to express the biggest gratitude to drg. Abu Bakar and Melkisedek Landi, S.Kep, Ns for helping collect data. The authors also thanks to Ns. Nurul Fauziah, S.Kep for assistance in writing the manuscript.

\section{Ethics committee approval}

This study has approval by the Medical and Health Research Ethics Committee (MHREC) from the Faculty of Medicine in Universitas Gadjah Mada.

\section{References}

Abela, J.C. (2009) Adult learning theories and medical education: a review, Malta Medical Journal, 21, 1, pp. 11-18.

Ahmad, B.E. \& Majid, F.A. (2010) Self-directed learning and culture: a study on Malay adult learners, Procedia Social and Behavioral Sciences, 7, pp. 254-263.

Ainoda, N., Onishi, H. \& Yasuda, Y. (2005) Definitions and goals of "self-directed learning" in contemporary medical education literature, Annals of the Academy of Medicine Singapore, 34, 8, pp. 515-519.

Bidokht, M.H. \& Assareh, A. (2011) Lifelong learners through problem-based and self-directed learning, Procedia Computer Science, 3, pp. 1446-1453.

Claramita, M., Nugraheni, M.D., van Dalen, J. \& van der Vleuten, C. (2013) Doctor-patient communication in Southeast Asia: a different culture? Advances in Health Sciences Education, 18, 1, pp. 15-31.

Cohen, L., Manion, L. \& Morrison, K. (2013) Research Methods in Education, London: Routledge.

Colton, D. \& Covert, R.W. (2007) Designing and Constructing Instruments for Social Research and Evaluation, San Francisco: Jossey Bass.

Deci, E.L. \& Ryan, R.M. (2013) Intrinsic Motivation Inventory (IMI) scale description [Internet] Available at: http://www. selfdeterminationtheory.org/quistionnaires/10question-naires/50 [Accessed 20 September 2013].

Directorate of Higher Education, Ministry of Education and Culture Republic of Indonesia 
and Faculty of Medicine UGM (1995) The Hedera Project - The Netherlands Government and Faculty of Medicine UGM.

Fisher, M., King, J. \& Tague, G. (2001) Development of a self-directed learning readiness scale for nursing education, Nurse Education Today, 21,7, pp. 516-525.

Frambach, J.M., Driessen, E.W., Chan, L.C. \& van der Vleuten, C.P. (2012) Rethinking the globalisation of problem-based learning: how culture challenges self-directed learning, Medical Education, 46, 8, pp. 738-747.

Harun, N.F., Yusof, K.M., Jamaludin, M.Z. \& Hassan, S.A.H.S. (2012) Motivation in problem-based learning implementation, Procedia - Social and Behavioral Sciences, 56, pp. 233-242.

Hmelo-Silver, C.E. (2004) Problem-based learning: what and how do students learn? Educational Psychology Review, 16, 3, pp. 235-266.

Khoo, H.E. (2003) Implementation of problem-based learning in Asian medical schools and students' perceptions of their experience, Medical Education, 37, 5, pp. 401-409.

Knowles, M.S. (1970) The Modern Practice of Adult Education (From Pedagogy to Andragogy) revised and updated chapter 4. What is andragogy. Cambridge: Adult Education, available at www.hospitalist. cumc.columbia.edu, [Accessed 16 March 2013.]

Lestari, E. \& Widjajakusumah, D. (2009) Students' self-directed learning readiness, perception toward student-centered learning \& predisposition towards student-centered behaviour, South East Asian Journal of Medical Education, 31, pp.52-56.

Loyens, S.M., Magda, J. \& Rikers, R.M. (2008) Selfdirected learning in problem-based learning and its relationships with self-regulated learning, Educational Psychology Review, 20, 4, pp. 411427.

Malta, S., Dimeo, S.B. \& Carey, P.D. (2010) Selfdirection in learning: Does it change over time? Journal of Allied Health, 39, 2, pp. e37-e41.
Mann, K., Dornan, T. \& Teunissen, P.W. (2011) Perspective on learning, In: Dornan, T. Mann, K. Scherpbier, A. \& Spencer [Eds.] Medical Education Theory and Practice, Edinburgh:Churchill Livingstone Elsevier, pp. 17-38.

McAuley, E., Duncan, T. \& Tammen, V.V. (1989) Psychometric properties of the intrinsic motivation inventory in a competitive sport setting; A confirmatory factor analysis, Research Quarterly for Excercise and Sport, 60, 1, pp. 48-58.

Merriam, S.B. (2001) Andragogy and self-directed learning: pillars of adult learning theory, New Directions for Adult and Continuing Education, 2001, 89, pp. 3-14.

Murad, M.H. \& Varkey, P. (2008) Self-directed learning in health professions education, Annals of the Academy of Medicine Singapore, 37, 7, p. 580.

Nenniger, P. (1999) On the role of motivation in selfdirected learning: The two-shells-model of motivated self-directed learning as a structural explanatory concept, European Journal of Psychology of Education, 14, 1, p. 71.

Schmidt, H. (2000) Assumptions underlying selfdirected learning may be false, Medical Education, 34, 4, pp. 243-245.

Smith, M.K. (2002) Malcolm Knowles, informal adult education, self-direction and andragogy, the encyclopedia of informal education. Viewed 9 March 2013, [Available at www.infed.org/thinkers/et-know.htm].

Triatmojo, N.N. (2013) Eksplorasi pengalaman mahasiswa kepaniteraan klinik dalam implementasi kurikulum berbasis kompetensi di fakultas kedokteran UGM, Mini thesis, Universitas Gadjah Mada.

Wahid, M.H. (2013) Analisis implementasi problembased learning: Studi kasus tunggal di fakultas kedokteran Universitas Indonesia, Dissertation, Universitas Gadjah Mada.

Williams, B. (2004) Self direction in a problem based learning program, Nurse Education Today, 24, 4, pp. 277-285. 